\title{
A glucomannan with $\alpha$-glucosidase inhibitory activity isolated from the leaves of Antidesma microcarpum Elmer (Euphorbiaceae)
}

\author{
John P. Paulin ${ }^{1 *}$, Mario A. Tan ${ }^{1-3}$, Grecebio Jonathan D. Alejandro ${ }^{1-3}, \mathcal{E}$ Mafel C. Ysrael $^{1,2}$ \\ ${ }^{1}$ The Graduate School; ${ }^{2}$ Research Center for the Natural and Applied Sciences; ${ }^{3}$ College of Science, \\ University of Santo Tomas, 1015 Manila, Philippines
}

\begin{abstract}
The $\alpha$-glucosidase inhibition is seen as a possible approach to controlling post-prandial hyperglycemia in diabetes mellitus. Some species of the genus Antidesma L. are reported to be of use in the treatment of diabetes. In search of indigenous and/or endemic Antidesma species with potential use as adjuvants of antidiabetic agents the extracts of A. curranii, A. fusicarpum, A. microcarpum, and A. montanum were screened for $\alpha$-glucosidase inhibitory activity and to isolate the active constituent from the most active extract. The Antidesma extracts were assayed by an in vitro method using yeast $\alpha$-glucosidase. The in vitro $\alpha$ glucosidase inhibitory assay was also used for the bioassay-guided isolation of the active constituent. A. microcarpum extract exhibited the highest glucosidase inhibitory activity with an $\mathrm{IC}_{50}$ of $1.42 \pm 0.03 \mu \mathrm{g} / \mathrm{mL}$. The bioassay-guided isolation of the active constituent in the extract of $A$. microcarpum afforded a glucomannan having the structure $\beta-D-$ mannopyranosyl-( $1 \rightarrow 3)-\alpha$-D-mannopyranosyl-( $1 \rightarrow 4)$-[ $\beta$-D-glucopyranosyl-( $(1 \rightarrow 3)]-\alpha-D$ glucopyranose and with an $\mathrm{IC}_{50} \alpha$-glucosidase inhibitory activity of $0.22 \pm 0.04 \mu \mathrm{g} / \mathrm{mL}$ which is higher than the inhibitory activity of standard acarbose.
\end{abstract}

Keywords: Antidesma microcarpum, Euphorbiaceae, $\alpha$-glucosidase inhibitory activity, glucomannan

\section{INTRODUCTION}

Diabetes mellitus is one of the leading causes of mortality in the Philippines [1]. By 2030, around 552 million individuals will have type 2 diabetes mellitus corresponding to $7.8 \%$ of the adult population [2]. Diabetic individuals have glucose intolerance, and intake of dietary carbohydrates causes postprandial hyperglycemia, in which blood glucose is elevated to abnormal levels [3].

*To whom correspondence should be addressed: paulin.johnp@gmail.com
Carbohydrates are converted into glucose through a hydrolytic cleavage catalyzed by membrane-bound $\alpha$-glucosidase found in the epithelium of the small intestines [4]. Inhibition of $\alpha$-glucosidase will slow down the hydrolysis of carbohydrates into glucose and control the build-up of blood glucose. Thus, $\alpha$-glucosidase inhibition is seen as a possible approach in improving postprandial hyperglycemia in type 2 diabetes mellitus.

The commonly prescribed $\alpha$-glucosidase inhibitors are acarbose and miglitol which are 
obtained from microbial sources. Meanwhile, plants that are indicated to lower blood glucose levels can also serve as potential sources of $\alpha$ glucosidase inhibitors. There are 47 species of plants belonging to 29 families exhibiting $\alpha$ glucosidase inhibitory activity [5] and the compounds responsible for this activity are terpenes, alkaloids, quinine, flavonoids, phenol, phenylpropanoid, and steride structures containing carboxylic acid, ester, alcohol, and allyl functional groups [6].

The genus Antidesma has about 170 species distributed in the world [7, 8]. Locals in Mauritius [9], Northeast India [10], and the Philippines [11] use Antidesma species as an antidiabetic agent. Inhibitory effect of different Antidesma species A. bunius [12, 13], A. celebicum [12, 14], A. madagascariense [15, 16], A. montanum [12], and A. nuerocarpum [12] on $\alpha$-glucosidase have been reported.

In an effort to search for $\alpha$-glucosidase inhibitors from either indigenous or endemic Antidesma species, extracts of $A$. curranii, A. microcarpum, A. montanum, and $A$. fusicarpum were screened for $\alpha$-glucosidase inhibition. The active constituent from the most active Antidesma extract was then isolated and identified.

\section{EXPERIMENTAL}

General. For 1D and 2D NMR, Bruker AV-500 (500 MHz) spectrometer was used; gel filtration chromatography was performed using Sephadex LH-20 (30 g 25-100 $\mu$ bead size, column diameter $=1.0 \mathrm{in}$., height $=10.0 \mathrm{in}$.) and preparative thin layer chromatography (TLC) using a pre-coated with silica gel $60 \mathrm{RP}-8 \mathrm{~F}_{254}$ plate $(0.25 \mathrm{~mm}$, Merck) and pre-coated silica-gel 60 F254 $(0.25 \mathrm{~mm}$, Merck) plates.

Plant materials and extraction. The leaves of A. curranii Merr. were obtained from Hermosa, Bataan while $A$. fusicarpum Elmer were collected from Pilar, Bataan. Samples of A. microcarpum Elmer and A. montanum Blume leaves were acquired from Lambunao, Iloilo. Collection was done between October 2014 and January 2015. The samples were authenticated by the UST Herbarium. Voucher specimens of A. curranii (USTH 012454), A. fusicarpum (USTH 012855), A. microcarpum (USTH 012455), and A. montanum (USTH 012456) were deposited at the Herbarium, Research Center for the Natural and Applied Sciences (RCNAS), University of Santo Tomas.

All air-dried leaves were extracted exhaustively with methanol based on the ratio of $1 \mathrm{~kg}$ dried leaves to $10 \mathrm{~L}$ solvent. After 3 days, the extracts were collected and subjected to rotary evaporation.

$\alpha$-Glucosidase inhibitory assay. The $\alpha$ glucosidase inhibition assay was performed according to a slightly modified procedure of Feng et al. [17]. In a 96-well plate, $20 \mu \mathrm{L}$ of $0.8 \mathrm{U} /$ $\mathrm{mL}$ yeast $\alpha$-glucosidase was mixed with $120 \mu \mathrm{L}$ of a test substance or acarbose in $0.5 \%$ DMSO. The solution was incubated at $37^{\circ} \mathrm{C}$ for $15 \mathrm{~min}$ then $20 \mu \mathrm{L}$ of $5.0 \mathrm{mM}$-nitrophenyl- $\alpha$-Dglucopyranoside was added. The plate was returned to the incubator and the reaction was allowed to proceed at $37^{\circ} \mathrm{C}$ for $15 \mathrm{~min}$. After incubation, $80 \mu \mathrm{L}$ of $0.2 \mathrm{M}$ sodium carbonate was added to stop the reaction. The absorbance of the contents of the plate were read at $405 \mathrm{~nm}$ using Hitachi SH-1000 microplate reader. Percent inhibition was calculated using the formula below.

$$
\text { Percent inhibition }=\frac{A_{\text {control }}-A_{\text {sample }}}{A_{\text {control }}} \times 100
$$

where $\mathrm{A}_{\text {control }}$ and $\mathrm{A}_{\text {sample }}$ are the absorbance of the control and sample respectively.

To determine the $\mathrm{IC}_{50}$ of the extracts for $\alpha$ glucosidase inhibition, a dose-response curve of five concentrations was prepared and each concentration was measured. The mean percent inhibition and standard deviation were reported. The $\mathrm{IC}_{50}$ values were calculated using four- 
parameter logistic equation through GraphPad Prism 6.07. The mean $\mathrm{IC}_{50}$ of the extracts on $\alpha$ glucosidase inhibition were compared to that of acarbose.

Isolation of the active glucomannan. The airdried leaves of $A$. microcarpum (262.4 g) were soaked in methanol $(2.6 \mathrm{~L})$ for $36 \mathrm{~h}$. The methanol extract was concentrated in vacuo to a green syrupy consistency. The concentrated extract $(20.54 \mathrm{~g})$ was suspended in water and successively partitioned with hexane $(500 \mathrm{~mL})$, ethyl acetate $(300 \mathrm{~mL})$, and $n$-butanol $(300 \mathrm{~mL})$ to obtain hexane $(2.60 \mathrm{~g})$, ethyl acetate $(6.20 \mathrm{~g})$, $n$-butanol (4.68 g) and aqueous (7.00 g) solublefractions after removal of solvents in vacuo. Each major fraction was tested for $\alpha$-glucosidase inhibitory activity.

The most active $n$-butanol soluble-fraction $(1.02 \mathrm{~g})$ was subjected to gel filtration chromatography on LH-20 Sephadex column eluting with methanol $(1 \mathrm{~L})$ to give 20 pooled sub-fractions based on similar TLC profiles. One of two active sub-fractions labelled BF7 appearing as a single component was purified by preparative TLC silica gel $60 \mathrm{RP}-8 \mathrm{~F}_{254}$ (Merck) plate developed in methanol:water $(1: 1, \mathrm{v} / \mathrm{v})$ to obtain the active glucomannan. The structure of the active glucomannan was determined by $1 \mathrm{D}$ $\left({ }^{1} \mathrm{H}-\mathrm{NMR}\right.$ and $\left.{ }^{13} \mathrm{C}-\mathrm{NMR}\right)$ and $2 \mathrm{D}$ (HMQC and HMBC) NMR spectral analysis. The isolate was dissolved in deuterated methanol $\left(\mathrm{CD}_{3} \mathrm{OD}\right)$ and its ${ }^{1} \mathrm{H}$ and ${ }^{13} \mathrm{C}$ NMR were recorded on a Bruker $\mathrm{AV}-500$ (500 MHz) spectrometer using trimethylsilane as internal standard.

\section{Results AND DISCUSSION}

$\alpha$-Glucosidase inhibitory activity. The $\alpha$ glucosidase inhibitory effect of the four Antidesma species varied with the concentration of the methanol extracts (Fig. 1). Based on this concentration-response curve, the $\mathrm{IC}_{50}$ value which indicated the extract concentration needed to inhibit $50 \%$ of enzyme activity, was determined through interpolation. Table 1 shows the $\mathrm{IC}_{50}$
Table 1. The $\alpha$-glucosidase inhibitory activity of the four Antidesma species with A. microcarpum having the highest activity

\begin{tabular}{|c|c|}
\hline Samples & $\begin{array}{c}\text { IC }_{50} \text { values }\left(\times 10^{3} \mathrm{ng} / \mathrm{mL}\right) \\
n=9\end{array}$ \\
\hline A. curranii & $10.03 \pm 0.26$ \\
\hline A. fusicarpum & $8.53 \pm 0.14$ \\
\hline A. microcarpum & $1.42 \pm 0.03$ \\
\hline A. montanum & $5.02 \pm 0.07$ \\
\hline Acarbose & $0.64 \pm 0.03$ \\
\hline
\end{tabular}

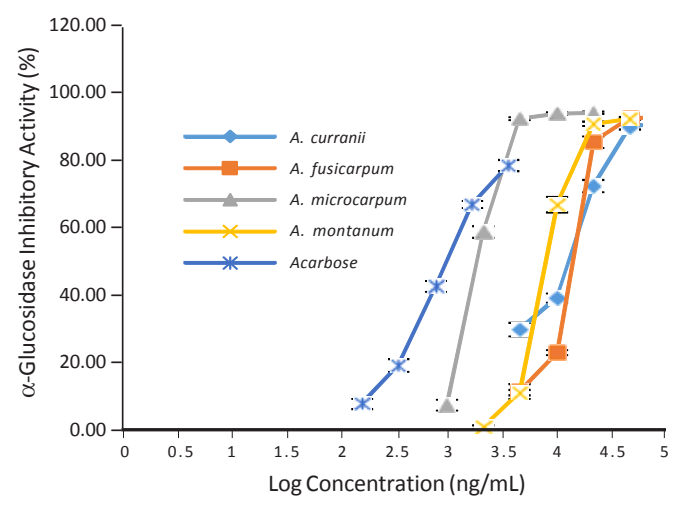

Figure 1. Concentration response curve of the Antidesma extracts and acarbose for $\alpha$ glucosidase inhibitory activity. Values are expressed as mean \pm standard deviation $(n=9)$.

values of the four Antidesma extracts and acarbose on $\alpha$-glucosidase. Among the Antidesma extracts, A. microcarpum was the most active with an $\mathrm{IC}_{50}$ at $1.42 \pm 0.03 \mu \mathrm{g} / \mathrm{mL}$. The results prompted the bioassay-guided isolation of the constituent with $\alpha$-glucosidase inhibitory activity from $A$. microcarpum.

The $\alpha$-glucosidase inhibitory activity of the major fractions of the methanolic extract of $A$. microcarpum decreased with the concentration of the solutions of the fractions, as shown by the plots in Fig. 2. The $\mathrm{IC}_{50}$ values of the different fractions are presented in Table 2. The $n$-butanol fraction was found to be the most active $\alpha$ glucosidase inhibitor with $\mathrm{IC}_{50}$ at $0.04 \pm 0.02 \mu \mathrm{g} /$ $\mathrm{mL}$. 
Table 2. The $\alpha$-glucosidase inhibitory activity of the major fractions of $A$. microcarpum

\begin{tabular}{|c|c|}
\hline Fraction & $\begin{array}{c}\text { IC }_{50} \text { values }\left(\times 10^{3} \mathrm{ng} / \mathrm{mL}\right) \\
n=9\end{array}$ \\
\hline Hexane & $9.70 \pm 0.27$ \\
\hline Ethyl Acetate & $9.78 \pm 0.28$ \\
\hline$n$-Butanol & $0.04 \pm 0.02$ \\
\hline Aqueous & $4.68 \pm 0.11$ \\
\hline
\end{tabular}

Table $3 .{ }^{13} \mathrm{C}$ and ${ }^{1} \mathrm{H}$ NMR Chemical Shifts of $\beta$ D-Mannopyranosyl-(1 $\rightarrow 3)-\alpha-D-$ mannopyranosyl-(1 $\rightarrow 4)$-[ $\beta$-D-glucopyranosyl$(1 \rightarrow 3)]-\alpha-D$-glucopyranose

\begin{tabular}{|c|c|c|}
\hline Monosaccharide & $\begin{array}{c}\text { Chemical Shift } \\
{ }^{13} \mathrm{C} \text { NMR, } \\
400 \mathrm{MHz}\end{array}$ & $\begin{array}{c}\text { Chemical Shift } \\
{ }^{1} \mathrm{H} \text { NMR, } \\
400 \mathrm{MHz}\end{array}$ \\
\hline $\begin{array}{c}\beta \text {-D-Mannopyranose } \\
1 \\
2 \\
3 \\
4 \\
5 \\
6 \\
\end{array}$ & $\begin{array}{l}98.3 \\
71.9 \\
74.9 \\
66.0 \\
78.1 \\
62.8 \\
\end{array}$ & $\begin{array}{c}4.55(J=9.0 \mathrm{~Hz}) \\
3.80 \\
3.50 \\
3.59 \\
3.28 \\
3.53,3.55 \\
\end{array}$ \\
\hline $\begin{array}{c}\alpha \text {-D-Mannopyranose } \\
1 \\
2 \\
3 \\
4 \\
5 \\
6 \\
\end{array}$ & $\begin{array}{l}99.2 \\
73.0 \\
71.3 \\
64.6 \\
76.3 \\
62.9 \\
\end{array}$ & $\begin{array}{c}5.11(J=4.5 \mathrm{~Hz}) \\
4.02 \\
3.69 \\
3.59 \\
4.04 \\
3.53,3.55 \\
\end{array}$ \\
\hline $\begin{array}{c}\beta \text {-D-Glucopyranose } \\
1 \\
2 \\
3 \\
4 \\
5 \\
6\end{array}$ & $\begin{array}{c}103.2 \\
76.9 \\
78.2 \\
71.8 \\
77.6 \\
64.4\end{array}$ & $\begin{array}{c}4.48(J=9.0 \mathrm{~Hz}) \\
3.28 \\
3.50 \\
3.38 \\
3.47 \\
3.59\end{array}$ \\
\hline $\begin{array}{c}\alpha \text {-D Glucopyranose } \\
1 \\
2 \\
3 \\
4 \\
5 \\
6\end{array}$ & $\begin{array}{l}94.0 \\
71.9 \\
83.4 \\
69.5 \\
73.9 \\
64.2\end{array}$ & $\begin{array}{c}5.40(J=4.5 \mathrm{~Hz}) \\
3.55 \\
3.66 \\
3.85 \\
4.04 \\
3.59\end{array}$ \\
\hline
\end{tabular}

Gel-filtration chromatography of the $n$-butanol fraction yielded two active sub-fractions, one of which is a single component (BF7) having an $\mathrm{IC}_{50}$ at $0.22 \pm 0.04 \mu \mathrm{g} / \mathrm{mL}$ which is higher than acarbose. The structure of purified BF7 is elucidated in this report. The other sub-fraction with higher activity than BF7 but with two

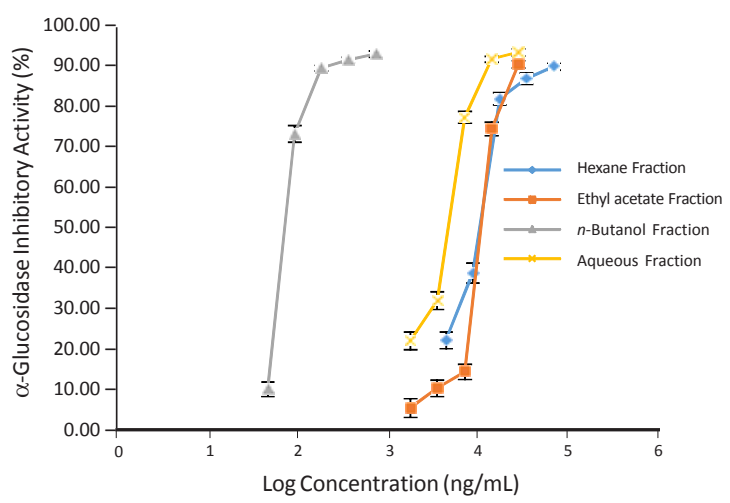

Figure 2. Concentration response curve by the $A$. microcarpum fractions for $\alpha$-glucosidase inhibitory activity. Values are expressed as mean \pm standard deviation $(n=9)$.

unidentified components acting together with BF7 to account for the high $\alpha$-glucosidase inhibitory activity of the butanol fraction.

Structure elucidation of BF7. The isolate BF7 (4.4 mg) was subjected to different NMR experiments to determine its structure. Table 3 presents the spectral data from the ${ }^{1} \mathrm{H}$ NMR and ${ }^{13} \mathrm{C}$ NMR experiments. Initial assessment of the spectra suggested that the isolate is a carbohydrate. Analysis of the ${ }^{1} \mathrm{H}$ NMR spectrum showed that the isolate contained four anomeric protons at $\delta_{\mathrm{H}} 4.48(\mathrm{~d}, J=9.0 \mathrm{~Hz}), \delta_{\mathrm{H}} 4.55(\mathrm{~d}, J=$ $9.0 \mathrm{~Hz}), \delta_{\mathrm{H}} 5.11(\mathrm{~d}, J=4.5 \mathrm{~Hz})$, and $\delta_{\mathrm{H}} 5.40(\mathrm{~d}, J=$ $4.5 \mathrm{~Hz}$ ) suggesting the presence of four monosaccharide residues. The tetrasaccharide consisted of two $\alpha$-anomers (5.11 and $5.40 \mathrm{ppm}$ ) and two $\beta$-anomers (4.48 and $4.55 \mathrm{ppm}$ ). Methine and methylene protons of the carbohydrate were observed between $\delta_{\mathrm{H}} 3.11$ and $\delta_{\mathrm{H}} 4.13 \mathrm{ppm}$.

The ${ }^{13} \mathrm{C}$ NMR spectrum showed four signals between 94.0 and $103.2 \mathrm{ppm}$ which were characteristic signals for anomeric carbons. This confirmed the presence of four monosaccharide residues. Among the four anomeric carbon signals, $\delta_{\mathrm{C}} 94.0$ corresponds to the reducing end of the tetrasaccharide. By comparing with known chemical shifts for ${ }^{13} \mathrm{C}$, for the anomeric carbons 


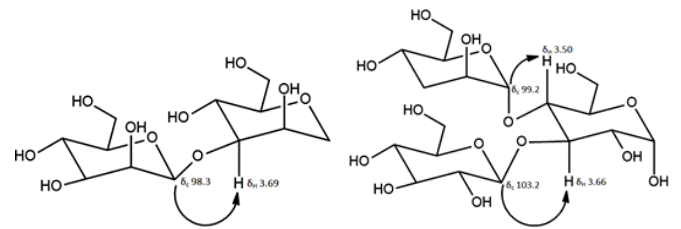

Figure 3. HMBC correlations at the glycosidic linkage

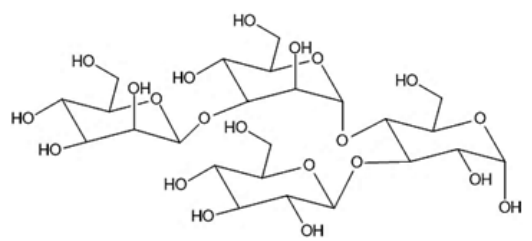

Figure 4. Structure of $\beta$-D-mannopyranosyl- $(1 \rightarrow 3)$ $\alpha$-D-mannopyranosyl- $(1 \rightarrow 4)$-[ $\beta$-D-glucopyranosyl$(1 \rightarrow 3)]-\alpha$-D-glucopyranose

of monosaccharides, $\delta_{\mathrm{C}} 94.0$ was characteristic for $\alpha$-D-glucose. Signals of the other anomeric carbons were shifted downfield. This indicated that these carbons were involved in a glycosidic linkage.

Also, the ${ }^{13} \mathrm{C}$ NMR spectrum showed four signals between $\delta_{\mathrm{C}} 62.8$ and $\delta_{\mathrm{C}} 64.4 \mathrm{ppm}$. These signals corresponded to four hydroxymethylene structures of aldopyranose. Based from known chemical shifts for C-6 of hexoses, the monosaccharide units were identified. The carbon signals $\delta_{\mathrm{C}} 64.2$ and $\delta_{\mathrm{C}} 64.4$ corresponded to two D-glucose units while signals $\delta_{\mathrm{C}} 62.9$ and $\delta_{\mathrm{C}} 62.8$ corresponded to two D-mannose units. The reducing end was glucose while the other residues had glycosylated $\mathrm{C}-1$.

The HMBC spectrum provided information on how the four monosaccharide units were linked (Fig. 3). The C-1 of $\beta$-D-mannose $\left(\delta_{\mathrm{C}} 98.3\right)$ was correlated to $\mathrm{H}-3$ of $\alpha$-D-mannose $\left(\delta_{\mathrm{H}} 3.69\right)$. The $\mathrm{C}$-1 of $\alpha$-D-mannose $\left(\delta_{\mathrm{C}}\right.$ 99.2) was correlated to $\mathrm{H}-4$ of $\alpha$-D-glucose $\left(\delta_{\mathrm{H}} 3.50\right)$. The C- 1 of $\beta$-Dglucose $\left(\delta_{\mathrm{C}} 103.2\right)$ was correlated to $\mathrm{H}-4$ of $\alpha$-D-glucose $\left(\delta_{\mathrm{H}} 3.66\right)$.
Based on the spectral data, the active constituent from A. microcarpum was found to be $\beta$-Dmannopyranosyl- $(1 \rightarrow 3)-\alpha-D-$ manno pyranosyl-( $1 \rightarrow 4)-[\beta$-D-glucopyranosyl- $(1 \rightarrow 3)]$ $\alpha$-D-glucopyranose (Fig. 4).

The structure of the isolated glucomannan may explain its $\alpha$-glucosidase inhibitory activity. The $\alpha$-glucosidase enzyme specifically breaks $\alpha$ $(1 \rightarrow 4)$ linkages of oligosaccharides of glucose units. Thus the mannose units linked by $\beta$ $(1 \rightarrow 3)$ in the structure of the glucomannan are not susceptible to hydrolysis by $\alpha$-glucosidase. The glucomannan structure may instead act to inhibit the activity of the $\alpha$-glucosidase by competition at the active site of the enzyme. This is the first report on the isolation of a glucomannan with $\alpha$-glucosidase inhibitory activity from $A$. microcarpum.

\section{Conclusion}

The $\alpha$-glucosidase inhibitory activity of $A$. microcarpum is an evidence for its potential utility as an adjuvant to post prandial hyperglycemia in diabetes mellitus. The structure of the active component, a glucomannan may account for the possible mechanism of $\alpha$ glucosidase inhibitory activity. The elucidation of the glucomannan may lead to alternative designs to the currently available $\alpha$-glucosidase inhibitors which have reports of undue gastro intestinal side effects.

\section{ACKNOWLEDgements}

The researchers would like to thank Dr. Atsushi Nakayama of Tokushima University for the NMR experiments and the Research Center for the Natural and Applied Sciences for the use of the facilities.

\section{REFERENCES}

[1] Department of Health. The 2010 Philippine Health Statistics 2013. http://www.doh.gov.ph/ sites/default/files/publications/ PHS2010_March13.compressed.pdf 
[2] International Diabetes Federation. Diabetes Atlas Fourth Edition. (Brussels, Belgium: International Diabetes Federation, 2009).

[3] Bischoff $H$. The mechanism of $\alpha$-glucosidase inhibition in the management of diabetes. Clinical and Investigative Medicine 1995; 18:303-11.

[4] Gavin JR. Pathophysiologic mechanisms of postprandial hyperglycemia. American Journal of Cardiology 2001; 88(Suppl.):4H-8H.

[5] Benella W, Bellahcen S, Bnouham M. Antidiabetic medicinal plants as a source of alpha glucosidase inhibitors. Current Diabetes Reviews 2010; 6:247-54. DOI:10.2174/ 157339910791658826.

[6] Yin Z et al. $\alpha$-Glucosidase inhibitors isolated from medicinal plants. Food Science and Human Wellness 2014; 3:136-74. DOI:10.1016/ j.fshw.2014.11.003.

[7] Pax F, Hoffmann P. EuphorbiaceaePhyllanthoideae-Phyllanthae. In: Engler A (Ed.) Das Pflanzenreich, 1922; 81:1-349.

[8] Elya B, Forestrania RC, Ropi M, Kosela S, Awang $\mathrm{K}$, Omar $\mathrm{H}$, Hadi HA. The new alkaloids from Antidesma cuspidatum M.A. Records of Natural Products 2014; 8:342-47.

[9] Gurib-Fakim A, Gueho J, Sewraj MD. Plantes Medicinales de Maurice (Volume I) Editions de L'ocean Indien. (Stanley, Rose Hill, Mauritius, 1996).

[10] Khan MH, Yadava PS. Antidiabetic plants used in Thoubal district of Manipur, Northeast India. Indian Journal of Traditional Knowledge 2010; 9:510-14.

[11] Chua-Barcelo RT. Ethno-botanical survey of edible wild fruits in Benguet, Cordillera administrative region, the Philippines. Asian Pacific Journal of Tropical Biomedicine 2014; 4:S525-538. DOI:10.12980/ APJTB.4.201414B36.
[12] Elya B, Basah K, Mun'im A, Yuliastuti W, Bangun A, Septiana EK. Screening of $\alpha$-glucosidase inhibitory activity from some plants of Apocynaceae, Clusiaceae, Euphorbiaceae, and Rubiaceae. Journal of Biomedicine and Biotechnology 2012. DOI:10.1155/2012/281078.

[13] Lawag IL, Aguinaldo AM, Naheed S, Mosihuzzaman M. $\alpha$-Glucosidase inhibitory activity of selected Philippine plants. Journal of Ethnopharmacology 2012; 144:217-19. DOI:10.1016/j.jep.2012.08.019

[14] Elya B, Katrin B, Utami NF, Marista GM, Anindita RA. Alfa-glucosidase inhibitory activity of kayu tuah (Antidesma celebicum). International Research Journal of Pharmacy 2013; 4:30-32. DOI:10.7897/2230-8407.041107

[15] Mahomoodally MF, Subratty AH, Gurib-Fakim A, Choudhary MI, Khan SN. Traditional medicinal herbs and food plants have the potential to inhibit key carbohydrate hydrolyzing enzyme in vitro and reduce postprandial blood glucose peaks in vivo. The Scientific World Journal 2012. DOI:10.1100/2012/285284.

[16] Picot CMN, Subratty AH, Mahomoodally MF. Inhibitory potential of five traditionally used native antidiabetic medicinal plants on $\alpha$-amylase, $\alpha$ glucosidase, glucose entrapment, and amylolysis kinetics in vitro. Advances in Pharmacological Sciences 2014. DOI:10.1155/2014/739834.

[17] Feng J, Yang X-W, Wang R-F. Bio-assay guided isolation and identification of $\alpha$-glucosidase inhibitors from the leaves of Aquilaria sinensis. Phytochemistry 2011; 72:242-47. DOI:10.1016/ j.phytochem.2010.11.025 